\title{
Reprocessing practices for gastrointestinal endoscopes: a multicentre study in Egyptian university hospitals
}

Rehab H. El-Sokkary', Ahmed A. Wegdan ${ }^{2}$, Ahmed A. Mosaad', Rasha H. Bassyouni ${ }^{2}$ and Wael M. Awad $^{3}$

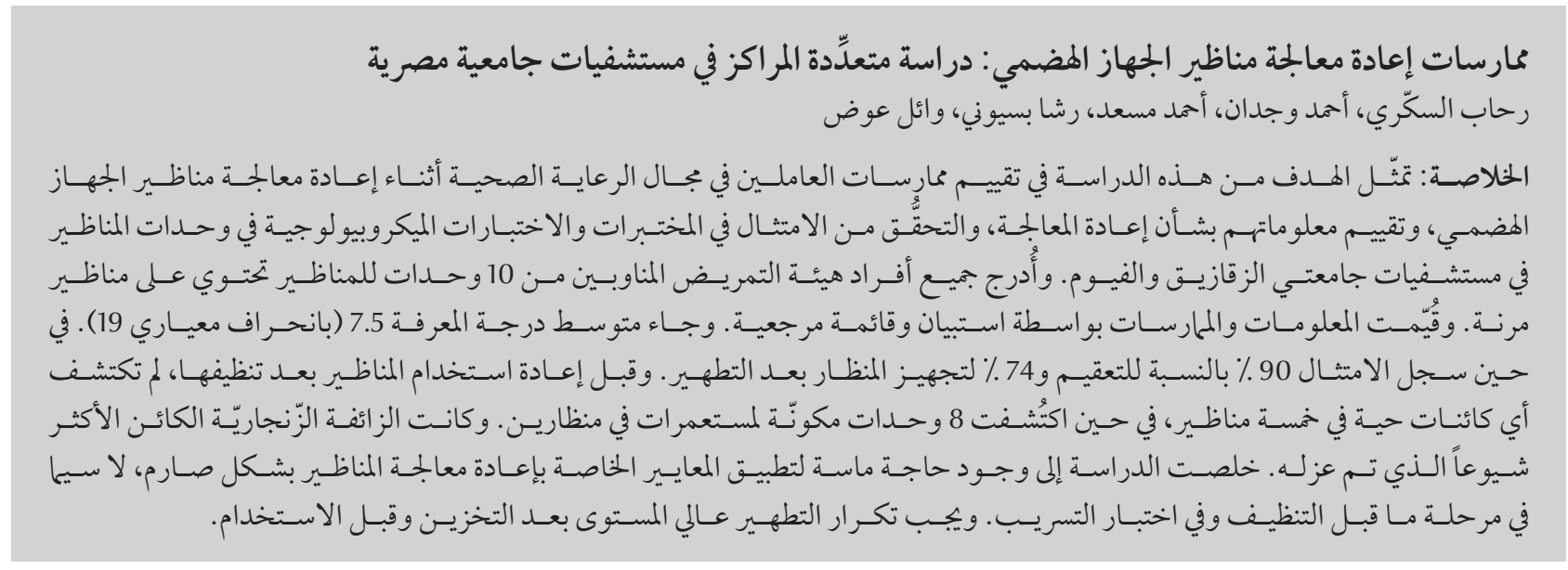

ABSTRACT The aim of this study was to assess the practices of health care workers during gasterointestinal endoscope reprocessing, evaluate their knowledge about reprocessing, and verify their compliance with laboratory and microbiological tests in endoscopy units at Zagazig University and Fayoum University hospitals. All nursing staff on duty from 10 endoscopy units, with 16 flexible endoscopes, were included. Knowledge and practice were assessed by a questionnaire and a checklist. The mean knowledge score was 7.5 (SD 1.9), which was poor. Compliance was $90 \%$ for disinfection and $74 \%$ for endoscope processing after disinfection. Before reuse after cleaning, no organisms were detected in 5 endoscopes, while 8 colony forming units were found in 2. Pseudomonas aeruginosa was the most common organism isolated. Strict implementation of the reprocessing guidelines are needed, especially the pre-cleaning stage and leak testing. Repeating high level disinfection after storage and before use must be followed.

\section{Pratiques de traitement des endoscopes gastro-intestinaux : étude multicentrique dans des hôpitaux} universitaires en Égypte

RÉSUMÉ La présente étude avait pour objectif d'évaluer les pratiques des agents de soins de santé lors du traitement des endoscopes gastro-intestinaux, de mesurer leur connaissance du traitement, et de vérifier leur bonne exécution des tests de laboratoire et des tests microbiologiques dans les unités d'endoscopie des hôpitaux universitaires de Zagazig et de Fayoum. Toutes les équipes de personnels infirmiers issues de 10 unités d'endoscopie, avec 16 endoscopes souples, ont été incluses dans l'étude. Les connaissances et les pratiques ont été évaluées par un questionnaire et une liste de contrôle. Le score de connaissance moyen était de 7,5 (ET1,9). La conformité était de 90 \% pour la désinfection, et de 74 \% pour le traitement des endoscopes après désinfection. Après nettoyage et avant réutilisation, aucun organisme n'a été détecté pour cinq endoscopes, et huit unités formant des colonies ont été trouvées dans deux autres endoscopes. Pseudomonas aeruginosa était l'organisme le plus couramment isolé. Une application stricte des directives de traitement est requise, notamment à l'étape du pré-nettoyage et des essais d'étanchéité. Il est important d'effectuer une désinfection de haut niveau répétée après entreposage et avant utilisation.

'Department of Medical Microbiology and Immunology, Faculty of Medicine, Zagazig University, Zagazig, Egypt (Correspondence to: Rehab H. El-Sokkary: rehab_elsokkary@yahoo.com). 2Department of Medical Microbiology and Immunology, Faculty of Medicine, Fayoum University, Fayoum, Egypt. ${ }^{3}$ Department of General Surgery, Faculty of Medicine, Zagazig University, Zagazig, Egypt.

Received: 15/09/16; accepted: 23/11/16 


\section{Introduction}

Appropriate reprocessing of endoscopes and their accessories is essential to safeguard patients and staff. Reprocessing flexible endoscopes involves multiple steps (cleaning, disinfection and sterilization) and adherence to the guidelines on reprocessing is essential (1). In Egypt, rules for this process have been figured out in the national guide for infection prevention and control (2), which is the standard for the country.

Information about staff practices in endoscopy units regarding reprocessing and their adherence to guidelines is needed to support the development of effective performance improvement (3). To our knowledge there have been no previous studies that have assessed these practices. Therefore, the objectives of this study were to: evaluate the practices of nursing staff during gastrointestinal endoscope reprocessing, assess their knowledge about reprocessing, and verify their compliance by laboratory and microbiological tests.

\section{Methods}

A cross-sectional multicentre study was carried out at the endoscopy units of Zagazig University Hospitals and Fayoum University Hospitals from March 2015 to September 2015. The study was approved by the institutional review boards of the Zagazig and Fayoum universities.

All functioning endoscopes were included - 16 flexible endoscopes from 10 endoscopy units. A total of 59 nursing staff in the units, who were responsible for cleaning and storage of the endoscopes, were enrolled. We excluded staff members who were on leave during the study period. No staff declined to participate and all gave their written consent.

The study was conducted in 2 phases: in phase one, the knowledge and compliance of health care workers were assessed and in phase two, laboratory and microbiological verification of compliance was determined.

Knowledge of the health care workers was assessed by a 21-question questionnaire $(4,5)$ in Arabic. It was prepared in Arabic for better understanding and to get more reliable results. The questionnaire was pilot tested on a sample of 15 nurses to determine its acceptability and the clarity of the questions, and to confirm its face validity; it was then modified accordingly. These staff were excluded from the final analysis. The questionnaire included 7 questions about personal and jobrelated variables (age, sex, place of work, duration of work in general, duration of work in endoscopy units, and training on endoscope reprocessing and awareness of reprocessing guidelines) and 13 scored questions about the reprocessing procedures at the facility. A correct answer was assigned a score of 1 , an incorrect answer was assigned a score of 0 . The total knowledge score was calculated by adding the number of correct answers. A mean score equal to and above the median was considered satisfactory knowledge, and a score below the median was considered unsatisfactory knowledge. The survey was distributed to and self-completed by all participants. All surveys were anonymous.

Evaluation of the compliance of health care workers was done using another 49-point self-completed questionnaire, adapted from the national guidelines (2), which were grouped under 7 areas. All criteria were marked as: compliant, not compliant or not applicable, and the percentage of compliance was calculated (6).

Laboratory verification of cleaning processes by protein assay was done as follows: $10 \mathrm{~mL}$ of rinse solution were collected after cleaning of the endoscope and before high level disinfection. Protein assay was done by the biuret method. The permissible level for organic and bioburden residuals is less than $6.4 \mu \mathrm{g} / \mathrm{mL}$ protein as described in a previous study (7).

Microbiological examination of endoscopes was done after storage and before being used again. Using aseptic technique, $10 \mathrm{~mL}$ of rinse solution were collected (7) from reprocessed endoscopes and a culture was done. Colony count and identification to species level was performed (8).

After bacterial culture and isolation, the bioburden level was estimated as follows: counts were reported as the number of colony forming units (cfu) per mL (9). Quantification of bacterial growth was done: no growth $=0 \mathrm{cfu}$, sparse growth $=<5 \mathrm{cfu} / \mathrm{mL}$, moderate growth $=5-20 \mathrm{cfu} / \mathrm{mL}$ and heavy growth $=>20 \mathrm{cfu} / \mathrm{mL}$ (10).

Statistical analysis was done using SPSS, version 15. Quantitative data are presented as ranges, means and standard deviations (SD). For qualitative data, numbers and percentages are presented. The Pearson correlation coefficient $(r)$ was used to assess the significance of association between protein and bioburden levels. A $P$-value less than 0.05 was considered statistically significant.

\section{Results}

A total of 46 health care workers were present at the time of the study and were enrolled: 43 were women. Their ages ranged from 25 to 53 years with a mean of 35.3 (SD 5.6) years. Duration of work in endoscopy units ranged from 3 months to 30 years. Most of the staff (78\%) were aware that there were reprocessing instructions available in the unit and 44\% had had training courses on endoscope reprocessing (Table 1).

The knowledge and compliance of health care workers are shown in Tables 2 and 3. The mean knowledge score about all reprocessing steps was 7.5 (SD 1.9), with a maximum of 13. The median score was 8.3 . The mean score for cleaning processes was 2.9 


\begin{tabular}{lr}
\hline Table 1 Personal and job-related variables & Values \\
\hline Variable & 3 \\
Sex (No.) & 43 \\
$\quad$ Male & \\
$\quad$ Female & $25-53$ \\
Age (years) & $35.3(5.6)$ \\
$\quad$ Range & \\
Mean (SD) & $17.5(6.3)$ \\
Duration of work in nursing (years) & \\
$\quad$ Range & $2(4.3)$ \\
$\quad$ Mean (SD) & $44(95.7)$ \\
$\quad$ Duration of work in endoscopy units (range) & \\
Previous experience in an endoscopy unit [(No. (\%)] & $35(77.8)$ \\
$\quad$ Only one unit & $10(22.2)$ \\
$\quad$ More than one unit & \\
Aware of available instructions about reprocessing? [(No. (\%)] & \\
$\quad$ Yes & $20(43.5)$ \\
$\quad$ No & $25(54.3)$ \\
\hline Had training courses on endoscope reprocessing [(No. (\%)] & \\
Yes &
\end{tabular}

(SD 0.75). All participants thought that after mechanical cleaning, immersible equipment should be thoroughly rinsed with water. On the other hand, only $47 \%$ of participants thought that endoscope should be checked by inspection and a leak test. The mean score for disinfection steps was 2.1 (SD 0.08): $98 \%$ of the participants knew that repeated entry into any chemical disinfectant and retained water on equipment can lower the concentration over time. On the other hand, $67 \%$ of participants knew that internal and external surfaces of the endoscope should be in contact with disinfectant for 20 minutes. The mean score for storage processes was 1.5 (SD $0.08)$. Only $6 \%$ of participants knew that control valves, distal hoods, caps, etc. should be removed prior to storage of the endoscope.

\section{Table 2 Knowledge of endoscope reprocessing among health care workers}

Reprocessing step

Cleaning

The cleaning brushes should be disposable/thoroughly cleaned and receive a high-level disinfection or sterilization after each use

All channels should be brushed and irrigated with large amounts of enzymatic presoak solution or detergent and tap water

After mechanical cleaning, immersible equipment should be thoroughly rinsed with water

The endoscope should be checked by inspection and leak test

All detachable parts should be removed and soaked in an enzymatic presoak solution

Disinfection

Internal and external surfaces and channels must be in contact with the disinfecting agent for at least 20 minutes

Repeated dipping into any chemical disinfectant and retained water on equipment can lower the concentration over time

All containers with glutaraldehyde solutions should be sealed or covered

Treatment after disinfection

Rinsing should be done with sterile water. If sterile water is not available, then potable tap water should be used with a rinse of the internal lumens with alcohol

Drying with alcohol and compressed air should be done between each patient when tap water is being used to rinse the endoscope channels

Drying with alcohol and compressed air should be done before storage whether tap water or sterile water is used

Endoscopes should be stored vertically in a cabinet

Control valves, distal hoods, caps, etc. should be removed before storage of the endoscope
Percentage who answered the question correctly 


\begin{tabular}{lc}
\hline Table 3 Compliance with specific policies, procedures and practices & Rate $^{\mathbf{1}(\%)}$ \\
\hline Reprocessing step & 67 \\
\hline Cleaning of endoscope & 90 \\
Disinfection of endoscope & 74 \\
Treatment of the endoscope after disinfection & 44 \\
Processing endoscopic accessory equipment & 0 \\
Hazardous materials' management & 61 \\
Endoscopy personnel occupational health issues ${ }^{2}$ & 58 \\
\hline
\end{tabular}

${ }^{1}$ Minimal compliance $=\leq 75 \%$, partial compliance $=76-84 \%$ and satisfactory compliance $=\geq 85 \%$ (7).

${ }^{2}$ Such as thorough hand hygiene before and after each procedure, use of personal protective equipment as needed, accessible personal protective equipment, vaccination against hepatitis $B$.

The results of the laboratory and microbiological verification of compliance are shown in Table 4. Protein levels ranged from 4.6 to $32.8 \mu \mathrm{g} / \mathrm{mL}$ with a mean of $14.8(\mathrm{SD} 8.9) \mu \mathrm{g} / \mathrm{mL}$. The highest level of protein $(32.8 \mu \mathrm{g} /$ $\mathrm{mL}$ ) was detected from endoscope numbers 5 and 15. Three endoscopes showed protein levels below the permissible level (i.e.< $6.4 \mu \mathrm{g} / \mathrm{mL}$ ), indicating the cleaning process was effective. The number of cfu ranged from 0 to 8 , with a mean of 2 (SD 5.8). Endoscope numbers 5 and 15 had the highest number of cfu (8 each), while no growth was detected from endoscope numbers 4 , $7,8,13$ and 14 . There was a statistically significant positive correlation between protein and bioburden levels $(r=0.589$, $P=0.03$ ).

While, endoscope numbers 4 and 14 showed no bacterial growth, the protein level was higher than the permissible level $(<6.4 \mu \mathrm{g} / \mathrm{mL})$. Only endoscopes numbers 7,8 and 13 showed no bacterial growth and permissible protein levels.

Pseudomonasaeruginosa was the most common isolated organism (30.8\%), followed by micrococcus (15.4\%), Serratia spp. (7.7\%), Staphylococcus saprophyticus (7.7\%) and diphtheroids $(7.7 \%)$. No growth was detected in $30.7 \%$ of samples.

\section{Discussion}

In the current study, more than three quarters of the staff were familiar with existing reprocessing policies. Astudy in the United States of America (USA) reported that only $35 \%$ of bronchoscopists and $45 \%$ of medical directors in bronchoscope units were familiar with any national reprocessing rules (4). Only about half of our study participants had received training on endoscope reprocessing. Continuous medical education is important for all staff members and should be considered in the planning of training programmes in the units studied. Guidelines might be valuable for detailing proper practices, however they are not necessarily effective in changing behaviour (11).

The participants in the current study had a poor mean knowledge score of 7.5 (SD 1.9). Similar results have been reported previously (4). A similar knowledge score about cleaning procedures was recorded in a study in the USA (3), except for the leak test step; $90 \%$ of staff in theirstudy (3) versus $47 \%$ in our study knew the endoscope should be checked by inspection and leak test. Compliance with national guidelines was achieved for disinfection steps with partial compliance for treatment of the endoscope after disinfection. Another study found that most practitioners complied with the established disinfection guidelines
(12), while Seoane-Vazquez and colleagues reported that the primary cause of endoscopy-related infections was poor reprocessing practices (13).

Despite the importance of the cleaning process, minimal compliance was reported for this area in the current study. Inadequate cleaning can leave excess biomaterial on the surface of an endoscope, even after multiple reprocessing. Appropriate cleaning reduces the amount of organic debris (14) that can interfere with high level disinfection. Missing or rushing through key steps is a common problem (15). In the present study, nearly half of the study participants knew that leak testing is a required step; this is much lower than a previous study (77\%) (3). The failure to perform a proper leak test could also have serious implications. This test detects any physical breaks to the exterior or interior of the endoscope. These physical breaks compromise the integrity of the endoscope and will damage the internal structures (i.e. electrical wires, light bundle, manipulation cables) of the endoscope, which are not designed to be in contact with fluids. These breaks may also create a reservoir for microorganisms to grow. Continuing to use a damaged endoscope could result in further damage and be costly (3).

The rates of compliance with guidelines for reprocessing were $27 \%$ and $50 \%$ in 2 separate studies (16). The present 


\begin{tabular}{|c|c|c|c|c|}
\hline Endoscope no. & $\begin{array}{c}\text { Bioburden } \\
\text { estimation (cfu) }\end{array}$ & Protein level $(\mu \mathrm{g} / \mathrm{mL})^{2}$ & P-value & $r$ \\
\hline 1 & 5 & 16.3 & 0.03 & 0.58 \\
\hline 2 & 3 & 15.6 & & \\
\hline 3 & 2 & 28.6 & & \\
\hline 4 & 0 & 10 & & \\
\hline 5 & 8 & 32.8 & & \\
\hline 6 & 4 & 12.3 & & \\
\hline 7 & 0 & 4.9 & & \\
\hline 8 & 0 & 5.1 & & \\
\hline 9 & 5 & 22.2 & & \\
\hline 10 & 2 & 8.1 & & \\
\hline 11 & 3 & 12 & & \\
\hline 12 & 1 & 15.6 & & \\
\hline 13 & 0 & 4.6 & & \\
\hline 14 & 0 & 9.1 & & \\
\hline 15 & 8 & 32.8 & & \\
\hline 16 & 3 & 28.6 & & \\
\hline \multicolumn{5}{|l|}{ Total level } \\
\hline Range & $0-8$ & $4.6-32.8$ & & \\
\hline Mean (SD) & $2(5.8)$ & $14.8(8.9)$ & & \\
\hline
\end{tabular}

${ }^{\prime}$ Results are the average of 3 repeated experiments.

${ }^{2}$ The proposed standard for permissible level is $6.4 \mu \mathrm{g} / \mathrm{mL}$.

$P<0.05$ was considered as statistically significant.

$r=$ Pearson correlation coefficient; cfu = colony forming units.

study results showed that there was minimal compliance for processing of endoscopic accessory equipment. This agrees with the results of another study which found that a third of respondents reported that they reused disposable accessories (12). Reuse of disposable accessories should be avoided so as to limit the likelihood of cross-infection between patients and staff (17). A lack of financial resources may lead to reuse so it is essential that an adequate budget is allocated to prevent reuse.

In the current study, there was minimal compliance with endoscopy personnel occupational health issues, including thorough hand hygiene before and after each procedure, use of personal protective equipment, accessible personal protective equipment and vaccination against hepatitis B. A study in Korea found that although most respondents reported having experienced occupational hazards, the majority (78\%) did not wear protective eyewear (17).

Unfortunately, no responses were recorded for dealing with hazardous materials. This suggests that occupational safety programmes are not properly implemented in the hospitals studied.

Visual inspection could be used to check for adequate cleaning. However, compliance with cleaning of flexible endoscope channels cannot be confirmed using visual inspection (7). Therefore, in our study, verification of efficient cleaning was done by estimating protein levels on the endoscope. A considerable amount of residual protein was detected, which exceeded a proposed standard for permissible levels $(6.4 \mu \mathrm{g} / \mathrm{mL})(7)$. A much lower result was obtained in a previous study, 0.1 and $0.22 \mu \mathrm{g} / \mathrm{mL}$ after total cleaning (7). This could be explained by poor adherence of the health care workers to the cleaning steps. This is supported by the low compliance rate for this step (67\%).

According to the national guidelines, repeating high level disinfection after storage and before use is highly recommended, yet it is often not done. Checking for storage efficacy by $\mathrm{mi}$ crobiological testing of the endoscope fluid wash was performed to confirm the importance of conducting this step. Our study showed that, on 4 out of 16 occasions, the reprocessing steps and storage conditions were sufficient to avoid bacterial contamination. In contrast, on 2 out of 16 occasions, the process was inadequate with moderate growth $(8 \mathrm{cfu} / \mathrm{mL})$ and in 10 out of 16 occasions there was sparse growth.

Given the sparse growth and the nature of the organisms, most probably the cleaning protocols were not followed and/or monitored on a regular basis (18). Our laboratory and microbiological findings confirmed the results 
about knowledge and compliance from the questionnaire, which showed deficiencies in the cleaning process. On the other hand, the moderate bacterial growth found and the organisms isolated indicate breaches in the reprocessing steps and/or storage conditions in some cases. This is an alarming sign which needs close monitoring to ensure that the reprocessing guidelines are implemented and closely adhered to. In the current study, detection of Pseudomonas spp. (especially P. aeruginosa) and other non-fermenting rods indicates insufficient final rinsing and incomplete drying of the endoscope or contaminated flushing equipment for the air/waterchannel (19).

\section{Conclusion}

Strict regulations are still needed for the endoscope cleaning process, especially the pre-cleaning stage and leak testing. Repeating high level disinfection after storage and before use should be strictly followed. An occupational safety programme is needed for staff working in endoscope units. Efforts are needed to overcome knowledge barriers and financial constraints so as to ensure proper reprocessing of endoscopes and avoid adverse health effects on patients and staff.

\section{Funding: None.}

Competing interests: None declared.

\section{References}

1. Kovaleva J, Meessen NE, Peters FT, Been MH, Arends JP, Borgers RP, et al. Is bacteriologic surveillance in endoscope reprocessing stringent enough? Endoscopy. 2009;41:913-6.

2. [Egyptian National guide for infection control. Part 2: Infection control in specialized units: Endoscopy unit. 3rd ed]. Arab Republic of Egypt: Ministry of Health and Population; 2016:40-50 [In Arabic].

3. Ofstead CL, Wetzler HP, Snyder AK, Horton RA. Endoscope reprocessing methods: a prospective study on the impact of human factors and automation. Gastroenterol Nurs. 2010;33(4):304-11.

4. Srinivasan A, Wolfenden L, Song X, Perl T, Haponik F. Prevention and control: bronchoscope reprocessing and infection: bronchoscopy-specific guidelines are needed. Chest. 2004;125:307-14.

5. Mortada EM, Zalat MM. Assessment of compliance to standard precautions among surgeons in Zagazig University Hospitals, Egypt, using the Health Belief Model. J Arab Soc Med Res. 2014;9:6-14.

6. Infection Control Nurses Association. Audit tools for monitoring infection control guidelines within the community setting. 2005 (file:///C:/Users/Fiona/Downloads/AuditTools2005. pdf, accessed 22 March 2017).

7. Alfa M, Fatima I, Nancy Olson N. Validation of adenosine triphosphate to audit manual cleaning of flexible endoscope channels. Am J Infect Control. 2013;41:245-8.

8. Forbes BA, Sahm DF, Weissfeld AS. Bailey and Scott's diagnostic microbiology. 12th ed. St. Louis: Mosby; 2007.

9. Gillespie EE, Kotsanas D, Stuart RL. Microbiological monitoring of endoscopes: 5-year review. J Gastroenterol Hepatol. 2008;23:1069-74.
10. Riley R, Beanland C, Bos H. Establishing the shelf life of flexible colonoscopes. Gastroenterol Nurs. 2002;25(3):114-20.

11. Measuring hand hygiene adherence: overcoming the challenges [Monograph]: Oakbrook Terrace (IL): The Joint Commission;2009 (https://www.jointcommission.org/assets/1/18/hh_monograph.pdf, accessed 22 March 2017)

12. Park S, Jang JY, Koo JS, Park JB, Lim YJ, Hong SJ, et al. A review of current disinfectants for gastrointestinal endoscopic reprocessing. Clin Endosc. 2013;46:337-41.

13. Seoane-Vazquez E, Rodriguez-Monguio R, Visaria J, Carlson A. Exogenous endoscopy-related infections, pseudoinfections, and toxic reactions: Clinical and economic burden. Curr Med Res Opin. 2006;22(10):2007-21.

14. Burdick JS, Hambrick D. Endoscope reprocessing and repair costs. Gastrointest Endosc Clin N Am. 2004;14:717-24.

15. Rutala WA, Weber DJ. How to assess risk of disease transmission to patients when there is a failure to follow recommended disinfection and sterilization guidelines. Infect Control Hosp Epidemiol. 2007;28:146-55.

16. Seol SY, Moon JS, Kae SH. Result report of endoscope reprocessing survey: 2002 and 2004. Korean J Gastrointest Endosc. 2005;30 S1:109S-18S.

17. Cho Y. Current Status of Endoscope Reprocessing in Korea Clin Endosc. 2015;48:1-3.

18. Riley R, Beanland C, Bos H: Establishing the Shelf Life of Flexible Colonoscopes. Gastroent nursing. 2001; 25(3): 114-119.

19. Hamed MMA, Shamseya MM. Dafa Alah IDAN, El Sawaf G. Estimation of average bioburden values on flexible gastrointestinal endoscopes after clinical use and cleaning: Assessment of the efficiency of cleaning processes. Alex J Med. 2015;51:95-103. 